\title{
Effects of Daily Oral $m$-Chlorophenylpiperazine in Elderly Depressed Patients Initial Experience with a Serotonin Agonist
}

\author{
Alan M. Mellow, Brian A. Lawlor, Trey Sunderland, \\ Edward A. Mueller, Susan E. Molchan, and Dennis L. Murphy
}

Six patients (mean age $62.5 \pm 7.6$ years) with major depression were treated for 2 weeks with the serotonin agonist $\mathrm{m}$-chlorophenylpiperazine (m-CPP), $80 \mathrm{mg} /$ day in a doubleblind, piü_úv-curitrolled, crossover-design pilot study. Two patients showed clinically significant improvement in depressive symptoms during active drug treatment, whereas two others showed modest effects. All patients tolerated the drug, with no major side effects and no changes in vital signs or in liver, renal, thyroid, or hematological function. Further studies are needed to determine the characteristics of the possible antidepressant effects of $\mathrm{m}-\mathrm{CPP}$; such work may yield greater understanding of the roie of serotonin in affective and other psychiatric disorders.

\section{Introduction}

Dysregulation in brain systems involving the neurotransmitter serotonin (5-HT) has long been postulated in the pathophysiology of affective and other neuropsychiatric disorders (Coppen et al 1972; Van Praag 1977; Murphy et al 1978; Meltzer and Lowy 1987). In particular, diminished serotonergic function has been proposed as playing a role in the development of depressive illness. Numerous studies involving cerebrospinal fluid, platelet, neuroendocrine, and postmortem measurements have shown decreased 5-HT levels and turnover in depressed patients (Coppen and Doogan 1988). In addition, many agents that enhance synaptic 5-HT function have antidepressant properties (Willner 1985). Most pharmacological treatment strategies have been aimed at general augmentation of central monoaminergic function. Recently, agents have been developed that may selectively alter 5-HT activity; these may prove to be particularly useful in certain psychiatric disorder subgroups (Traber and Glaser 1987; Murphy et al 1989b).

From the Department of Psychiatry, Geropsychiatry Program, University of Michigan Medical Center, Ann Arbor, Mi 481041687 (A.M.M.), the Department of Psychiatry, Mount Sinai Medical Center, New York, NY 10029 (B.A.L.), the Laboratory of Clinical Science, Unit on Geriatric Psychopharmacology, National Institute of Mental Health, Bethesda, MD 20892 (T.S., S.E.M., D.L.M.), and Rutland Mental Health Services, Inc., Rutland, VT 0 057 (E.A.M.).

Address reprint requests to Dr. Alan M. Mellow, Geropsychiatry Program, University of Michigan Medical Center, 1103 Erst Huron, Ann Arbor, MI 48104-1687.

Received January 11, 1990; revised March 21, 1990. 
$m$-Chlorophenylpiperazine ( $m$-CPP), a metabolite of the heterocyclic antidepressant trazodone, has been found to act as a direct 5-HT receptor agonist in both animals and humans (Fuller et al 1981; Mueller et al 1985a, 1986). Initially, $m$-CPP was thought to be a selective 5- $\mathrm{HT}_{1 \mathrm{~B}}$ agonist in humans; however, biochemical studies have shown an absence of $5-\mathrm{HT}_{1 \mathrm{~B}}$ receptors in human brain. Furthermore, $m$-CPP has recently been shown to bind with similar affinity for all 5- $\mathrm{H}^{r} \mathrm{r}$ receptor subtypes that are present in human brain (Hamik and Peroutka 1989). Recent animal studies (Kennett and Curzon 1988; Kennett et al 1989) suggest that some behavioral effects of $m$-CPP may involve stimulation of the 5-HT $\mathrm{IC}_{1 \mathrm{C}}$ receptor subtype. During the past several years, the physiological, neuroendocrine, and behavioral responses to a single $m$-CPP dose (in the acute challenge strategy) have been used as indices of serotonergic responsivity in normal subjects as well as certain clinical populations (Mueller et al. 1985b; Murphy et al 1986, 1989a; Mellow et al 1988a).

Although many data have accumulated on the acute effects of $m$-CPP, nothing is known of the effects of its chronic administration in humans. Fuller et al (198i) onginally suggested that $m$-CPP derived by metabolism from trazodone might contribute to the latter's antidepressant effect. In animal studies, $m-C P P$ has been administered on a daily basis for 2 weeks and produced tolerance to the locomotor effects of a subsequent serotonergic challenge (Sills et al 1985). In light of what is known of the role of serotonin in depression, and, in particular, as $m$-CPP afforded a novel means of directly altering 5-HT function, we instituted a pilot study in depressed patients to examine the possible behavioral effects of $m$-CPP when administered on a daily basis. We herein report our experience with the first six patients who received $m$-CPP in a double-blind, placebocontrolled trial. A preliminary version of this work has appeared in abstract form (Mellow et al 1988b).

\section{Methods}

Six consecutive patients meeting DSM-III-R criteria (American Psychiatric Association 1987) for major depression were studied wlile inpatients on the NIMH Unit on Geriatric Psychopharmacology. All patients were screened to exclude any serious medical illness, and all were free of any other psychotropic drugs and were maintained on a low monoamine diet for 3 weeks prior to and during the experimental drug trial. $m$-CPP or identical placebo capsules were administered orally under double-blind conditions. All nursing staff and at least one evaluating psychiatrist were blind to the treatment conditions throughout the study. Every patient receivec. - 2-week placebo period, followed by a 2-week active drug period, followed by a crossover back to placebo for an additional 2 weeks (A-B-A design). Two patients (see below) received an additional drug and placebo period (A-B-A-B-A design). Aciive drug was given at a maximum dose of $80 \mathrm{mg} / \mathrm{day}$, in divided doses (20 mg QID). This dose and regimen was chosen primarily on the basis of what we knew patients could tolerate in our previous acute challenge studies (Muelier et al 1986). Hamilton Depression Rating Scales (HDRS) (Hamilton 1960) were completed weekly. Laboratury chemistries, including complete blood count (CBC), liver, kidney, and thyroid function tests, and urinalysis were monitored twice weekly. All patients gave informed consent, and received the drug under a protocol approved by the NIMH Intramural Clinical Research Subpanel. $m$-CPP monohydrochloride was purchased from Aldrich Chemical Company (Milwaukee, WI) and analyzed for purity with high-pressure liquid chromatography by the NIH Pharmaceutical Development Service. 
Table 1. Serial HDRS Ratings in Six Depressed Patients Receiving $m$-CPPa

\begin{tabular}{lccccc}
\hline Patient & PBO1 & $m$-CPP & FBO2 & $m$-CPP2 & PBO3 \\
\hline JP & 18 & 9 & 19 & 12 & 22 \\
GE & 21 & 15 & 25 & 13 & 30 \\
GS & 22 & 13 & 17 & & \\
HB & 27 & 21 & 26 & & \\
MK & 23 & 21 & 26 & & \\
HH & 17 & 18 & 17 & & \\
\hline
\end{tabular}

${ }^{a}$ Each value represents successive 2-week observation end-point ratings. PBO, placebc; CPP, $m$-CPP, 20 mg QID. See text for case reports.

Results

The clinical features and response of each patient in the study are described in the case reports below. The HDRS ratings on all six patients are summarized in Table 1 .

\section{Case 1}

J.P. was a 60-year-old man, a retired mathematician, with a 10-year history of depression and poor functioning, with one suicide atternpt several years previously. During the 4 years prior to admission, he had had chronic symptoms of anergy, middle and late insomnia, poor concentration, depersonalization, and derealization. He had also had periods of generalized anxiety and problems with impulse control. He had been treated with a variety of antidepressants and lithium, without relief of his symptoms, except for a partial, transient response to trazodone. The patient's medical and neurological examination at the NIMH showed mild cerebral atrophy on computed tomography (CT) scan and psychometric testing consistent with depression, and was otherwise unremarkabie. After a period of evaluation, the patient entered our $m$-CPP protocol in which he underwent, under double-blind conditions, several 2-week periods of both $m$-CPP, at a dose of $20 \mathrm{ng}$ QID, and identical placebo capsules. During the first period, the patient received placebo, and remained behaviorally unchanged from the evaluation period, with symptoms of dysphoria, anger, irritability and passive suicidal ideation. He then received $m$-CPP, and within 3 days became less irritable, depressed, and angry, both by subjective and objective evaluation. After 2 weeks, he was switched back to placebo and he soon returned to being anxious, hostile, and dysphoric. During a second $m$-CPP trial, the patient again had an improvement in all his symptoms. His only side effect during the active drug periods was very mild morning sedation, although this was so minimal that it did not disrupi the blindedness of the drug administration. Vital signs and all laboratory studies remained normal throughout the course of the study. A graphical record of serial HDRS ratings during the placebo and $m$-CPP trials is shown in Figure 1. At the end of the experimental protocol, Mr. P was treated with open-label buspirone, up to $35 \mathrm{mg} /$ day. Although used primarily in the treatment of anxiety disorders, buspirone, also a serotonin agonist, may have some therapeutic efficacy in depression (Schweizer et al 1986; Robinson et al 1989). Mr. P experienced a partial response to this treatment, on which he was discharged. As an outpatient, he again developed symptoms of dysphoria, anxiety, and hostility while on buspirone. He was switched to trazodone by his local psychiatrist in another state, and failed to respond. That physisian obtained a compassionate IND for $m$-CPP, and Mr. P. is reportedly doing well as an outpatient on $m$-CPP, $20 \mathrm{mg}$ QID. 


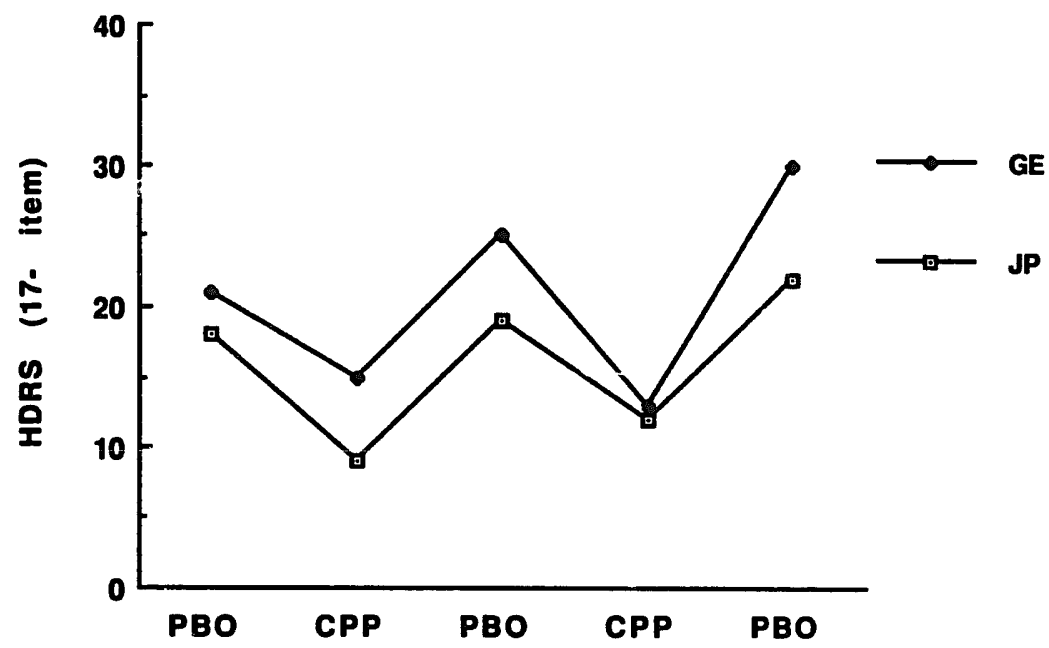

Figure 1. Serial HDRS ratings in two depressed patients who received $m$-CPP in an A-B-A-B$A$ design. Each point represents successive 2-week observation end-point ratings. PBO, placebo; CPP, $m$-CPP, $20 \mathrm{mg}$ QID. Ses text for case reports.

\section{Case 2}

G.E. was a 52-year-old wirow admitted for symptoms of major depression, with sad mood, insomnia, feelings of hopelessness, anxiety (with panic attacks) and several suicide attempts by cverdose. She had had almost chronic symptoms since her husband's death 4 years previously, and had been unresponsive to several antidepressants and electroconvulsive therapy (ECT). Her medical/neurological evaluation at the NIMH was entirely unremarkable. When admitted to our unit, Ms. E was taking imipramine, $75 \mathrm{mg}$ at bedtime and alprazolam $0.25 \mathrm{mg}$ TiD. She was withdrawn from this regimen, and had some increase in her already severe major depressive symptoms. After a 3-week drugfree and 2-week placebo period, she began a trial of $m$-CPP, $20 \mathrm{mg}$ QID, and, within several days, had a marked improvement in mood, energy, and sleep, and a decrease in anxiety and suicidal ideation; she had no side effects or laboratory changes during the trial. After 2 weeks, she was crossed back to placebo, whereupon she quickly became increasingly depressed and suicidal. A second 2-week trial of $m$-CPP was ajain effective in improving her depressive symptoms; during a second placebo period she again worsened considerably. Ms E's serial HDRS ratings are also shown in Figure 1. A double-blind trial of trazodone, up to $400 \mathrm{mg} / \mathrm{day}$, was unsuccessful; the patient was subsequently treated with ECT with a partial remission of symptoms.

\section{Case 3}

G.S. was a 60-year-old married woman with a 5-year history of depression and intermittent confusion. Her symptoms initially consisted of anxiety and hypochondriasis, but during the 2 years prior to admission, she had developed short-term memory difficulties, problems getting lost, as well as sad mood, crying spells, and suicidal ideation. Laboratory studies were all normal, but a cranial CT scan showed diffuse atrophy and psychometric testing showed a pattern consistent with mild dementia. Ms. S was felt to be suffering from both major depression and primary degenerative dementia. She 
received a 2-week trial of $m \cdot \mathrm{CPP}, 20 \mathrm{mg}$ q.i.d., with a modest improvement in her mood and energy compared with placebo, although no improvement in cognitive function. There were no side effects or laboratory abnormalities. She became considerably more depressed when crossed back to placebo.

Case 4

H.B. was a 63-year-old widower with a 25-year history of recurrent major depression that had previously been responsive to ECT but was refractory to treatment in the 2 years after his wife died. His symptoms included insomnia, low energy, anhedonia, poor concentration, and suicidal ideation. After a placebo period, he received $m$-CPP, $20 \mathrm{mg}$ QID, and had a mild improvement in his mood after 10 days of active drug treatment, during which he had no side effects or abnormal laboratory studies. This effect was not sustained after placebo substitution, and the patient was later treated successfully with tranylcypromine.

\section{Case 5}

M.K. was a 65-year-old married woman with a 20-year history of recurrent major depression that had become resistant to treatment with tricyclic and monoamine oxidase (MAO) inhibitor antidepressants, as well as ECT in the 2 years prior to admission. She had severe sleep disturbance, crying spells, anhedonia, fatigue, and diurnal variation in mood. Ms. $\mathrm{K}$ showed no significant improvement in her symptoms while receiving $m-\mathrm{CPP}, 20 \mathrm{mg}$ QID, and no side effects or abnormal laboratery studies. She did, however, experience a marked but transient increase in anxiety in the first 3 days after crossing back to placebo.

\section{Case 6}

H.H. was a 75-year-old widow with a history of hypertension and glaucoma who developed persistent symptoms of major depression after her husband's death 2 years previously. She had failed to respond to tricyclic antidepressants and MAO inhibitors and had had a transient response to ECT. On admission she was withdrawn, had mildly depressed mood, anhedonia, and psychomotor retardation. She had no significant behavioral change while receiving placebo, $m$-CPP, $20 \mathrm{mg}$ QID, or after withdrawal of active medication. There were no side effects or laboratory abnormalities during the course of treatment.

\section{Discussion}

This pilot study represents, to our knowledge, the first clinical trial of daily oral administration of the serotonin agonist $m$-chlorophenylpiperazine as a possible therapeutic agent in humans. The drug was safe and well tolerated at the maximum dose used of $80 \mathrm{mg} /$ day. In our preliminary series, two patients showed a clinically meaningful response to the drug, two patients had a modest clinical response, and two showed no clinical improvement. The relatively acute effects during active drug treatment as well as the rebound worsening observed after drug discontinuation are consistent with direct agonist stimulation of 5-HT receptors as a possible mechanism of action for the drug in this setting, as has been proposed for the action of the newer serotonergic anxiolytic agents such as 
buspirone (Young and Glennon 1988). Of particular interest is the fact that the two patients showing the most marked response had clinical features that included aggressivity and suicidality, behaviors for which 5-HT dysfunction has been proposed (Åsberg et al. 1987; Roy and Linnoila 1988).

This is clearly a preliminary study, and several factors limit the generalizability of the findings. Because of referral patterns to the NIMH, our patients were atypical in having refractory illness. One patient had concurrent dementia, which could have influenced her sensitivity to a serotonergic agonist (Lawlor et al. 1989b). Our patients were also older, and this might influence clinical response, because changes in 5-HT functioning occur with normal aging (Morgan 1937; Lawlor et al. 1989a). Ir addition, our sample size is still quite small in this pilot study. Finally, the 2-week drug trial duration is certainly much shorter than any accepted antidepressant trial; we chose this as a practical minimum time over which we might reliably observe early behavioral change or toxicity. Despite these limitations, we feel this report is an important first step in examining the potential of $m$-CPP as a therapeutic agent. Further studies are needed to confirm a true therapeutic effect of this agent, broaden the age range studied, identify potential depressive subtypes that might show a selective response (Van Praag et al. 1987), and determine optimim dose and duration parameters in the use of $m$-CPP. Such studies may also lead to a greater understanding of the role of serotonin in depression and other neuropsychiatric disorders.

The authors wish to acknowledge the assistance and support of the NIH Clinical Center 6-D nursing staff during the conduction of this study.

\section{References}

American Psychiatric Association (1987): Diagnostic and Statistical Manual of Mental Disorders, 3rd ed rev. Washington, DC: American Psychiatric Press.

Åsberg M, Schalling D, Träskman-Bendz L, Wägner A (1987): Psychobiology of suicide, impulsivity, and related phenomena. In Meltzer HY (ed), Psychopharmacology: The Third Generation of Progress. New York: Raven, pp 655-668.

Coppen AJ, Doogan DP (1988): Serotonin and its place in the pathogenesis of depression. J Clin Psychiatry 49(suppl):4-11.

Coppen A, Prange AJ Jr, Whybrow PC, Noguera R (1972): Abnormalities of indoleamines in affective disorders. Arch Gen Psychiatry 26:474-478.

Fuller RW, Snoddy HD, Mason NR, Owen JE (1981): Disposition and pharmacological effects of $m$-chlorophenylpiperazine in rats. Neuropharmacology 20:155-162.

Hamik A, Peroutka SJ (1989): 1-(m-chiorophenyl)piperazine ( $m$-CPP) interactions with neurotransmitter receptors in the human brain. Biol Psychiatry 25:569-575.

Hamilton M (1960): A rating scale for depression. $j$ Neurol Neurosurg Psychiatry 23:56-62.

Kennett GA, Curzon G (1988): Evidence that $m$-CPP may have behavioral effects mediated by central 5-HT ${ }_{1 C}$ receptors. Br J Pharmacol 94:137-147.

Kennett GA, Whitton P, Shah K, Curzon G (1989): Anxiogenic-like effects of $m$-CPP and TFMPP in animal models are opposed by 5-HT 1 receptor antagonists. Eur J Pharmacol 164:445-454.

Lawlor BA, Sunderland T, Hill JL, et al (1989a): Evidence for a decline with age in behavioral responsivity to the serotonin agonist, $m$-chlorophenylpiperazine, in healthy human subjects. Psychiatry Res 29:1-10.

Lawlor BA, Sunderland T, Mellow AM, Hill JL, Molchan SE, Murphy DL (1989b): Hyperresponsivity to the serotonin agonist $m$-chlorophenylpiperazine in Alzheimer's disease: A controlled study. Arch Gen Psychiatry 46:542-549. 
Mellow AM, Aulakh CS, Murphy DL (1988a): Neuroendocrine effects of serotonergic agents: Applications to the study of central serotonin function in humans. In Rech RH, Gudelsky GA (eds), 5-HT Agonists as Psychoactive Drugs. Ann Arbor: NPP Books, pp 259-282.

Mellow AM, Lawlor BA, Sunderland T, Mueller EA, Molchan SE, Murphy DL (1988b): A pilot clinical trial of $m$-chlorophenylpiperazine in depression. Presented at the American Psychiatric Association Meeting, Montreal, May.

Meltzer HY, Lowy MT (1987): The serotonin hypothesis of depression. In Meltzer HY (ed), Psychopharmacology: The Third Generation of Progress. New York: Raven, pp 513-526.

Morgan LG (1987): The dopamine and serotonin systems during aging in human and rodent brain: A brief review. Prog Neuropsychopharmacel Biol Psychiatry 11:153-157.

Mueller EA, Murphy DL, Sunderland T, Jones J (1985a): A new postsynaptic serotonin agonist for studies in humans. Psychopharmacol Bull 21:701-704.

Mueller EA, Sunderland T, Murphy DL (1985b): Neuroendocrine effects of $m$-chlorophenylpiperazine, a serotonin agonist in humans. J Clin Endocrinol Metab 61:1179-1184.

Mueller EA, Murphy DL, Sunderland T (1986): Further studies of the putative serotonin agonist, $m$-chlorophenylpiperazine: Evidence for a serotonin receptor mediaied mechanism of action in humans. Psychopharmacology 89:388-391.

Murphy DL, Campbell IC, Costa JL (1978): The brain serotonergic system in the affective disorders. Prog Neuropsychopharmacol 2:5-31.

Murphy DL, Mueller EA, Garrick NA, Aulakh CS (1986): Use of serotonergic agents in the clinical assessment of central serotonin function. J Clin Psychiatry 47(suppl):9-15.

Murphy DL, Mueller EA, Hill JL, Tolliver TJ, Jacobsen FM (1989a): Comparative anxiogenic, neuroendocrine, and other physiologic effects of $m$-chlorophenylpiperazine given intravenously or orally to healthy volunteers. Psychopharmacology 98:275-282.

Murphy DL, Zshar J, Benkelfat C, Pato MT, Pigott TA, Insel TR (1989b): Obsessive compulsive disorder as a 5-HT subsystem-related behavioural disorder. Br J Psychiatry 155(suppl 8):1524.

Peroutka SJ, Switzer JA, Hamik A (1989): Identification of 5-hydroxytryptamine-1D binding sites in human brain membranes. Synapse 3:61-66.

Robinson DS, Alms DR, Shrotriya RC, Messina M, Wickramaratne P (1989): Serotonergic anxiolytics and treatment of depression. Psychopathology 22 (suppl 1):27-36.

Roy A, Linnoila M (1988): Suicidal behavior, impulsiveness and serotonin. Acta Psychiatr Scand 78:529-535.

Schweizer EE, Amsterdam J, Rickels K, Kaplan M, Droba M (1986): Open trial of buspirone in the treatment of major depressive disorder. Psychopharmacol Bull 22:183-185.

Sills MA, Lucki I, Frazer A (1985): Development of selective tolerance to the serotonin behavioral syndrome and suppression of locomotor activity after repeated injection of either 5-MeODMT or $m$-CPP. Life Sci 36:2463-2469.

Traber J, Glaser T (1987): 5-HT ${ }_{1 \mathrm{~A}}$ receptor-related anxiolytics. Trends Pharmacol Sci 8:432-437.

Van Praag HM (1977): New evidence of serotonin-deficient depressions. Neuropsychobiology 3:5663.

Van Praag HM, Kahn R, Asnis GM, Lemus CZ, Brown SL (1987): Therapeutic indications for serotonin-potentiating compounds: A hypothesis. Biol Psychiatry 22:205-21\%.

Willner P (1985): Antidepressants and serotonergic neurotransmission: An integrative review. Psychopharmacology 85:387-404.

Young R, Glennon RA (1988): Second generation anxiolytics and serotonin. In Rech RH, Gudelsky GA (eds), 5-HT Agonists as Psychoactive Drugs. Ann Arbor: NPP Books, pp 239-258. 